\title{
EVALUATION OF THE EFFECT OF INTRA-ARTICULAR INJECTION OF MACROLIDE ANTIBIOTICS VERSUS CORTICOSTEROIDS ON INTERNAL DERANGEMENT OF TEMPOROMANDIBULAR JOINT
}

\author{
Mohamed Ihab Mosleh* and Amr Amin Ghanem**
}

\begin{abstract}
Temporomandibular disorders (TMD) are conditions clinically characterized by pain and dysfunction in the masticatory muscles, temporomandibular joints (TMJs), and adjacent structures. The goal of treatment for TMDs is elimination or reduction of pain and maintain normal temporomandibular joint function, preventing further joint damage, and reducing disease-related morbidities. The aim of this study was to assess the efficacy of intra-articular injection of macrolides versus corticosteroids in improving outcomes after temporomandibular joint (TMJ) arthrocentesis in internal derangement (ID) of the joint due to anteriorly non reducing disc displacement. The study included 24 patients with internal derangement of the temporomandibular joint who did not respond to conservative treatment for 3 months. Patients were randomly divided into 2 equal groups according to the intra-articular drug injected after arthrocentesis. In group I, a corticosteroid is injected and in group II a macrolide with a known anti-inflammatory effect is used. Pain, mouth opening and analysis of Tumor Necrosis Factor- $\alpha$ (TNF- $\alpha$ ) concentration were used as indicators of symptoms alleviation and patients improvement. In both groups, the median pain scores and MMO measurements after three months showed statistically significant lower values compared to pre-operative ones. In Conclusion, intra-articular injection of Azithromycin is comparable to corticosteroids injection as an effective method for treatment of the underlying disease process of internal derangement of the TMJ and alleviation of disease associated symptoms, such as pain and limitation of mouth opening.
\end{abstract}

KEY WORDS: TMJ, internal derangement, TNF- $\alpha$., Azithromycin, Corticosteroids, intraarticular injection.

\section{INTRODUCTION}

Internal derangement is a broad term that encompassesmore than simply a disc displacement. It also involves inflammation, changes in the articular surfaces, alteration in joint pressure and synovial fluid. Furthermore, it includes production of biochemical substances and factors as oxidative stresses due to clenching and parafunctions. Production of reactive Oxygen species (ROS) has

\footnotetext{
* Department of Oral and Maxillofacial Surgery, Faculty of Dentistry, Beni-Suef University, Beni Suef, Egypt

** Department of Oral and Maxillofacial Surgery, Faculty of Dentistry, Ain Shams University, Cairo, Egypt.
} 
also been found to result in subsequent induction of molecular events that may amplify tissue damage and TMJ dysfunction ${ }^{(1-3)}$. Oxidative stress markers might have promising potential as biomarkers in the diagnosis and therapeutic planning of TMJ disorders (2).Three mechanisms of injury are suggested, namely the direct mechanical injury where free radicals are generated by direct mechanical damage, the hypoxia reperfusion injury mechanism causing transient blood flow disruption resulting in tissue hypoxia, and the neurogenic inflammation mechanism and activation of pro-inflammatory cytokines ${ }^{(4)}$.

Many studies ${ }^{(5-7)}$ proved the presence of inflammatory mediators in the synovial fluid of the TMJ of patients having ID. These include Bradykinin, Prostaglandin E2, Interleukins and Tumor Necrosis Factor alpha TNF- $\alpha{ }^{(8-10)}$ with different concentrations. TNF- $\alpha$ is one of the pro-inflammatory cytokines involved in the pathogenesis in TMD. It is secreted by monocytes and macrophages. TNF- $\alpha$ has shown not only to be an inflammatory mediator but also a modulator of bone resorption. The mechanism includes exerting a catabolic effect through inducing synthesis of proteases and secretion of collagenases by fibroblasts. This results in an increased rate of cartilage extracellular matrix degradation and consequent proteoglycan depletion ${ }^{(11,12)}$.

Immuno-staining studies clearly show the presence of a significant amount of TNF- $\alpha$ in rheumatoid synovial tissue and osteoarthritis. This suggests TNF- $\alpha$ to be relevant to these disease processes. ${ }^{(8-14)}$. Therefore, TNF- $\alpha$ concentration in the synovial fluid may provide some prediction into their possible role in TMD and can be used as a marker of pain and to follow outcome to treatment ${ }^{(15)}$.

The main objective of arthrocentesis is to wash out inflammatory mediators, release the disc adhesions, eliminate pain and improve joint mobility ${ }^{(16)}$. Arthrocentesis has been proven to be a reversible, simple, safe, highly efficient, inexpensive procedure that can be performed repeatedly for management of patients with disc displacement and degenerative TMDs ${ }^{(17-20)}$. This procedure avades all complications associated open surgical ${ }^{(21)}$.

Arthroscopy though is an expensive procedure that needs special training skills; it has gained wide acceptance due to its physical action of lysis and lavage of the superior joint space ${ }^{(5)}$.

Arthrocentesis occurs in three steps: forcing apart the joint constituents, washing away inflammatory mediators and degradable products, lysis of adhesions and eliminating intra-articular effusion to decrease intra-articular pressure. High success rates have been reported for internal derangements (ID) and closed lock ${ }^{(19,22)}$. Better results and recapturing of the anteriorly displaced disc in terms of mouth opening and pain were obtained in acute closed lock cases than in chronic ones. ${ }^{(23)}$.

Repeated arthrocentesis proved to be more successful at reducing pain and improving MMO than a single intervention in the treatment of TMJ closed lock ${ }^{(24)}$. However, repeated injection of single corticosteroid injection was safe with the return of joint structures to its normal cellular structure after two weeks while double injection with six weeks apart resulted in irreversible damage to the components of the joint and three injections with six weeks apart resulted in massive destruction to most of the temporomandibular joint structures ${ }^{(25)}$.

Various drugs such as Morphine, local anesthetic agent, sodium hyalorunate and corticosteroids have been injected in the TMJ in conjunction with arthrocentesis to enhance its clinical outcome and provides long term effect on TMJ pain ${ }^{(26,27)}$.

The Simultaneous application of splint had no additional effect on the effectiveness of arthrocentesis for the treatment of unilateral disc displacement ${ }^{(28)}$.

Intraarticular corticosteroids after arthrocentesis have a potential anti-inflammatory effect on synovial tissues. They are known to reduce effusion, provide 
log term palliative effect on subjective symptoms, decrease joint pain and bring about an increase in the range of motion of the synovial joint ${ }^{(29,30)}$. Recently some complications were reported upon corticosteroids intra-articular injection namely skin depigmentation, depression zone adjacent to the site of injection and subcutaneous lipoatrophy, TMJ arthralgia and degenerative joint disease related to $10 \mathrm{mg}$ methylprednisolone injection at 3 weeks follow-up visit ${ }^{(31)}$.

The evidence so far documented showed that macrolides antibiotics do exert both local and systemic anti-inflammatory affects in humans and animals ${ }^{(32-36)}$. The mechanism posed was through affecting several ways of the inflammatory process such as migration of neutrophils, oxidative burst in phagocytes and production of prostaglandin cytokines and subsequent decrease in IL-1, IL6, IL-8, IL-4, IL-5, TNF- $\alpha$ as well as inhibition of pro- inflammatory cell mediators release and survival $^{(35)}$. The exact mechanisms of action for the macrolides that have this anti-inflammatory action are still not completely defined. It is known that they act by various molecular, cellular, and bacterial mechanisms.

Azithromycin significantly inhibited TNF- $\alpha$ production by $36 \%$ only at the highest dose used $(40 \mathrm{mg} / \mathrm{kg})^{(32)}$.This fact suggested that these agents can exert therapeutic effects independently of their antibacterial activity by inhibiting cytokines production. This could be through interfering with protein production and modulation of gene expression (33). Ertas et al (34) concluded that erythromycin might be preferable in the treatment of TMJ inflammation in rabbits because of its antiinflammatory effect and its potentially lesser side effects compared to corticosteroids. On the other hand, erythromycin proved useful for prevention and treatment of aseptic loosing which results from an inflammatory response to wear debris shed (high molecular weight polyethelene particles- induced inflammatory osteolysis) from total joint replacement ${ }^{(37,38)}$.

Beyond the anti-inflammatory properties of the macrolides, the 14- and 15-membered macrolides potentially have a very large number of both short and long-term immunomodulatory uses. Since they provide the majority of the same benefits as a corticosteroid, but do not cause immunosuppression, it is possible that they may become a favoured agent for patients who require systemic long term corticosteroids ${ }^{(33)}$. The immunomodulatory properties of azithromycin imply that an unkonwn shortterm biphasic effect on inflammation modulation and enhancement of host defence may exist ${ }^{(33)}$. Azithromycin (AZM), a 15-member macrolide antibiotic, is known to benefit patients based on their anti-inflammatory activity in macrophages rather than their antibacterial activity ${ }^{(39)}$. Reports that the potency of some macrolide antibiotics, especially those that are repeatedly discussed for the treatment of rheumatic diseases, have anti-inflammatory effects ${ }^{(32,36,40,41)}$. Macrolides are advocated in treatment of chronic sinusitis, coronary artery disease, rosacea, and psoriasis,Crohn's disease, and in the treatment of arthritis, undifferentiated connective tissue disease, and progressive recurrent multifocal osteomyelitis ${ }^{(32,36,41-43)}$.

This study aims to assess the anti-inflammatory effect of macrolides in cases of internal derangement of the temporomandibular joint .

\section{MATERIALS AND METHODS}

This prospective multicenter study included 24 patients suffering from TMD. The study was conducted in accordance with the Declaration of Helsinki in ethical issues and was approved by the Institutional Ethics Committee. The inclusion criteria for selecting the patients consisted of unilateral painful TMD, fulfilling the diagnostic criteria of internal derangement (ID) of TMJ according to Wilkes classification (44) grade III/ intermediate 
stage and did not respond to conservative treatments for 3 months. Owing to these criteria; the patients signs and symptoms included multiple episodes of pain and tenderness in the joint region and muscles of mastication, limitation of mouth opening, together with mechanical symptoms of intermittent catching or locking, restriction of motion as well as radiographic evidence of functional changes in the integrity of articulating surfaces and MRI suggestive of moderate anterior disc displacement, mild anatomical disc deformity (prolapse and thickening) with no hard tissue changes. All the selected patients were adult, healthy, who were subjected to conservative treatment for three months with no improvement which included nonsteroidal anti-inflammatory drugs, muscle relaxants, thermotherapy in form of heat application, physiotherapy and muscles exercises, soft diet regimen and splint therapy. All patients were free of any systemic diseases that might cause or reflect joint pain and dysfunction or interfere with their treatment.The exclusion criteria were as follows: hypersensitivity to any of the drugs injected, TMJ infections or surrounding structures, presence of a known connective tissue or autoimmune disease, prior TMJ surgery, degenerative joint disease, Rheumatoid osteoarthritis, history of major joint trauma, dentofacial deformity, and concurrent use of steroids, muscle relaxants, anxiolytics or narcotics. Before the trial, every patient was informed about the treatment procedure and the potential complications and a signed informed consent was obtained from all patients.

Preoperative assessment for data collection included patient history, duration of signs and symptoms, intensity of pain, maximum mouth opening, muscles tenderness, and joint dysfunction. The clinical examination and diagnosis were made by one investigator, and the patients were sent for a radiological examination by the same surgeon to confirm the diagnosis. Radiographic examination was done by panoramic views and MRI to assess disc position, joint effusion, disc deformity and articular bone changes. All the patients were assessed clinically and the following variables were recorded: joint pain using a visual analogue scale VAS (0-10), where zero represents no pain, 1-4 mild pain, 5-6 moderate pain and 7-10 severe pain. Maximum mouth opening (MMO) was measured at the maximum pain free mouth opening as the distance between the upper and lower incisors along the mid line. A complete record of the base line clinical data and parameters were obtained at the initial examination visit before starting the treatment.The outcome data were collected one week, and three months postoperatively.

\section{Pretreatment sampling:}

All Patients were subjected to Arthrocentesis with lactated Ringers and were then allocated randomly, using the envelop method, into two equal groups according to the drug injected: in group I; arthrocentesis was done followed by injection of 1 $\mathrm{ml}$ methyl prednisolone $40 \mathrm{mg}$ (Methylprednisolone acetate, Pharmacia \& Upjohn co. division of Pfizer Inc New York. NY10017] into the SJS.In group II, $1 \mathrm{ml}$ of Azithromycin $100 \mathrm{mg} / \mathrm{ml}$ vial (Zithromax Ben Venue Laboratories USA Pfizer INC. USA) was similarly injected.

\section{Synovial fluid sampling}

Patients were anesthetized by auricular alveolar nerve block; using mepivicaine 2\% 1:100.000 epinephrine. Arthrocentesis was done by marking two points on the skin along the cantho-tragal line. Before arthrocentesis a posterior inlet 21 gauge needle connected to a $10 \mathrm{~cm}$ syringe filled with $2 \mathrm{ml}$ lactated Ringer solution was introduced into the SJS and injected through the posterior point and immediately aspirated, re-injected and aspirated, then transferred to a sterile free Pyrogen tube, centrifuged to remove cells and stored at $70 \mathrm{C}^{\circ}$ until assayed for TNF- $\alpha$ analysis. 


\section{Treatment and follow up}

A second 21 gauge needle was inserted in the anterior point as an outflow needle and lavage was done using $200 \mathrm{ml}$ of lactated Ringer's solution. During lavage patient was instructed to open and close to allow for free flow of the solution and enhance the washing action. The anterior outflow needle was then removed and $1 \mathrm{ml}$ of methyl prednisolone $40 \mathrm{mg} / \mathrm{ml}$ was injected in the SJS via the inflow needle in group I and $1 \mathrm{ml}$ of Azithromycin 100mg/ $\mathrm{ml}$ in group II. Postoperative care included cold application for 4-6 hours, nonsteroidal anti-inflammatory analgesic Ibuprofen tid for 2 days (Brufen 400 mg KahiraPharm. \& Chem. Ind. Co., under licence from: Abbot Laboratories), physiotherapy in form of hot fomentation and muscle exercises to rehabilitate and stretch the muscles.

Criteria for clinical resolution or improvement of signs and symptoms were decrease of pain where it becomes no longer a main complaint or interfering with joint functions, and increase in range of joint movements.Outcomes were assessed and compared using the American Association of Oral and Maxillofacial Surgeons AAOMS sets of success criteria ${ }^{(44-47)}$ where $\mathrm{MMO} \geq 35 \mathrm{~mm}$ and visual analogue scale [VAS] score $\leq 3$. Synovial fluid samples were collected for immunoassay at 1 week and 3 months interval to detect and quantify TNF- $\alpha$ factor concentration. Patients were assessed clinically for MMO and pain at 1 week and 3months postoperatively. All postoperative data recordings were performed by a blinded to the groups independent observer..

\section{Analysis of Tumor Necrosis Factor- $\alpha$}

Synovial fluid TNF- $\alpha$ analysis was performed by a blinded examiner and determined by immunoenzymometric assay (Medgenix TNF- $\alpha$ EASIA kit, BioSource Europe Sa, Zoning Industriel B-6220, Fleurus, Belgium) using a streptavidin alkaline phosphatase conjugate and ensuring chromogenic substrate reaction for the quantitative measurements of humans TNF- $\alpha$ in serum, plasma, cell culture medium or other biologic fluids. The TNF- $\alpha$ concentration of samples, for which absorbance, are those of the last standard plotted at $450 \mathrm{~nm}$. If any sample had an absorbance greater than the absorbance of the last standard read at 450 $\mathrm{nm}$, a second reading at $490 \mathrm{~nm}$ (reference filter: 630 or $650 \mathrm{~nm}$ ) had to be done. So the first reading gave the high sensitivity of the essay and the second reading allowed an extended standard range.

\section{Statistical analysis}

Numerical data were explored for normality by checking the distribution of data and using tests of normality (Kolmogorov-Smirnov and ShapiroWilk tests). Age, MMO data showed normal (parametric) distribution while pain scores and TNF- $\alpha$ concentrations data showed non-normal (non-parametric) distribution. Parametric data were presented as mean, standard deviation (SD) and 95\% Confidence Interval (95\% CI) values. Nonparametric data were presented as median and range values. For parametric data, Student's t-test was used to compare between mean age values in the two groups. Repeated measures ANOVA test was used to compare between mean MMO in the two groups as well as to study the changes by time within each group. Bonferroni's post-hoc test was used for pair-wise comparisons when ANOVA test is significant. For non-parametric data, Mann-Whitney $\mathrm{U}$ test was used to compare between the two groups. Friedman's test was used to study the changes by time within each group. Dunn's test was used for pair-wise comparisons. Spearman's correlation coefficient was used to determine the correlation between TNF- $\alpha$ concentration, pain and MMO. Qualitative data were presented as frequencies and percentages. Fisher's Exact test was used for comparisons between the groups. The significance level was set at $P \leq 0.05$. Statistical analysis was performed with IBM SPSS Statistics for Windows, Version 23 .0. Armonk, NY: IBM Corp. 


\section{RESULTS}

The study included 24 patients; 17 female and 7 male, group I (9 female and 3 males), age ranging 19-43 years (mean 27.4 \pm 6.7 ), group II (8 females and 4 males), age ranging17- 38 years (mean 26.9 \pm 6.1 ). All patients suffered from joint pain, muscle tenderness, jaw deviation to the affected side and limitation of mouth opening without joint sounds. Clinical findings showed that all patients experienced pain immediately postoperative and for 24 hours after lavage and injection. Preauricular swelling, due to perfusion of the intracapsular tissues with the irrigating solution, was noted immediately after the lavage and resolved in few hours later as reported by all patients in the two groups. Muscle tenderness was alleviated completely within one week.

\section{Pain (VAS) scores}

All patients in the two groups suffered from pain preoperatively. There was no statistically significant difference between median pain scores in the two groups preoperatively, after one week as well as after three months $(P$-value $=0.447$, Effect size $=$ $0.31),(P$-value $=0.7$, Effect size $=0.154)$ and $(P$ value $=0.894$, Effect size $=0.047)$, respectively. There was a marked significant decrease in VAS in both groups at one week and three months postoperatively when compared to preoperative values. As regards the changes by time in each group, there was a statistically significant change in pain scores by time $(P$-value $<0.001$, Effect size $=0.95)$ and $(P$-value $<0.001$, Effect size $=0.964)$, respectively. Pair-wise comparisons between the time periods revealed that there was a statistically significant decrease in median pain scores after one week as well as from one week to three months. In both groups, the median pain scores after three months showed statistically significantly lower values compared to pre-operative score (Table 1, Figure1).

\section{Maximum Mouth Opening (MMO)}

There was no statistically significant difference between mean MMO in the two groups preopera- tively, after one week as well as after three months $(P$-value $=0.117$, Effect size $=0.108),(P$-value $=$ 0.184 , Effect size $=0.079)$ and $(P$-value $=0.658$, Effect size $=0.009)$, respectively.

As regards the changes by time in each group, there was a statistically significant change in MMO by time $(P$-value $<0.001$, Effect size $=0.834)$ and $(P$-value $<0.001$, Effect size $=0.876)$, respectively. Pair-wise comparisons between the time periods revealed that there was a statistically significant increase in mean MMO after one week as well as from one week to three months. In both groups, the mean MMO after three months showed statistically significantly higher values compared to preoperative measurement (Table 2, Figure 2).

\section{TNF- $\alpha$ concentration}

In this study, all patients had mediators in the TMJ synovial fluid indicating an inflammatory process, which supported the clinical diagnosis of TMJ inflammatory condition. The synovial fluid mediator profile observed in this study was evident among the two groups. The results of the TNF- $\alpha$ assay of the collected Synovial fluid samples revealed the presence of the cytokine in concentrations decreasing throughout the study course. There was no statistically significant difference between median TNF- $\alpha$ concentrations in the two groups preoperatively, after one week as well as after three months $(P$-value $=0.84$, Effectsize $=0.083),(P$-value $=0.603$, Effect size $=0.213)$ and $(P$-value $=0.954$, Effect size $=0.024)$, respectively. As regards the changes by time in Group I, there was a statistically significant change in TNF- $\alpha$ concentrations by time $(P$-value $=0.001$, Effect size $=0.632)$. Pair-wise comparisons between the time periods revealed that there was a statistically significant decrease in median TNF- $\alpha$ concentration after one week as well as from one week to three months. The median TNF- $\alpha$ concentration after three months showed statistically significantly lower values compared to pre-operative concentration. In Group II, there was a statistically significant change in TNF- $\alpha$ 
concentrations by time $(P$-value $<0.001$, Effect size $=0.771)$. Pair-wise comparisons between the time periods revealed that there was no statistically significant change in median TNF- $\alpha$ concentrations after one week, followed by statistically significant decrease in median concentration from one week to three months. The median TNF- $\alpha$ concentration after three months showed statistically significantly lower values compared to pre-operative concentration (Table 3, Figure 3).

TABLE (1) Descriptive statistics and results of Mann-Whitney $U$ test for comparison between pain scores in the two groups and Friedman's test for the changes by time within each group

\begin{tabular}{|c|c|c|c|c|c|c|}
\hline \multirow[t]{2}{*}{ Time } & \multicolumn{2}{|c|}{$\begin{array}{l}\text { Group I } \\
(\mathrm{n}=12)\end{array}$} & \multicolumn{2}{|c|}{$\begin{array}{l}\text { Group II } \\
(\mathrm{n}=12)\end{array}$} & \multirow[t]{2}{*}{$P$-value } & \multirow[t]{2}{*}{ Effect size $(d)$} \\
\hline & Median & Range & Median & Range & & \\
\hline Pre-operative & $8^{\mathrm{A}}$ & $5-10$ & $7^{\mathrm{A}}$ & $4-10$ & 0.447 & 0.31 \\
\hline 1 week & $4^{\text {B }}$ & $0-6$ & $4^{\text {B }}$ & $0-6$ & 0.700 & 0.154 \\
\hline 3 months & $0^{\mathrm{C}}$ & $0-3$ & $0^{\mathrm{C}}$ & $0-3$ & 0.894 & 0.047 \\
\hline$P$-value (Changes by time) & \multicolumn{2}{|c|}{$<0.001 *$} & \multicolumn{2}{|c|}{$<0.001 *$} & & \\
\hline Effect size $(w)$ & \multicolumn{2}{|c|}{0.95} & \multicolumn{2}{|c|}{0.964} & & \\
\hline
\end{tabular}

*: Significant at $P \leq 0.05$, Different superscripts in the same column indicate statistically significant changes by time.

TABLE (2) Descriptive statistics and results of repeated measures ANOVA test for comparison between MMO (mm) in the two groups as well as the changes by time within each group

\begin{tabular}{|c|c|c|c|c|}
\hline Time & $\begin{array}{l}\text { Group I } \\
(\mathrm{n}=12)\end{array}$ & $\begin{array}{l}\text { Group II } \\
(\mathrm{n}=12)\end{array}$ & $P$-value & $\begin{array}{c}\text { Effect size (Partial Eta } \\
\text { Squared) }\end{array}$ \\
\hline \multicolumn{5}{|l|}{ Pre-operative } \\
\hline Mean (SD) & $28.3(3.6)^{\mathrm{C}}$ & $25.4(5)^{\mathrm{C}}$ & 0.117 & 0.108 \\
\hline $95 \% \mathrm{CI}$ & $25.7-31$ & $22.8-28$ & & \\
\hline \multicolumn{5}{|l|}{1 week } \\
\hline Mean (SD) & $35.3(2.8)^{\mathrm{B}}$ & $33.4(3.9)^{\text {в }}$ & 0.184 & 0.079 \\
\hline $95 \% \mathrm{CI}$ & $33.3-37.4$ & $31.4-35.5$ & & \\
\hline \multicolumn{5}{|l|}{3 months } \\
\hline Mean (SD) & $40.2(2.2)^{\mathrm{A}}$ & $39.8(2.4)^{\mathrm{A}}$ & 0.658 & 0.009 \\
\hline $95 \% \mathrm{CI}$ & $38.8-41.5$ & $38.4-41.1$ & & \\
\hline$P$-value (Changes by time) & $<0.001^{*}$ & $<0.001 *$ & & \\
\hline Effect size (Partial Eta Squared) & 0.834 & 0.876 & & \\
\hline
\end{tabular}




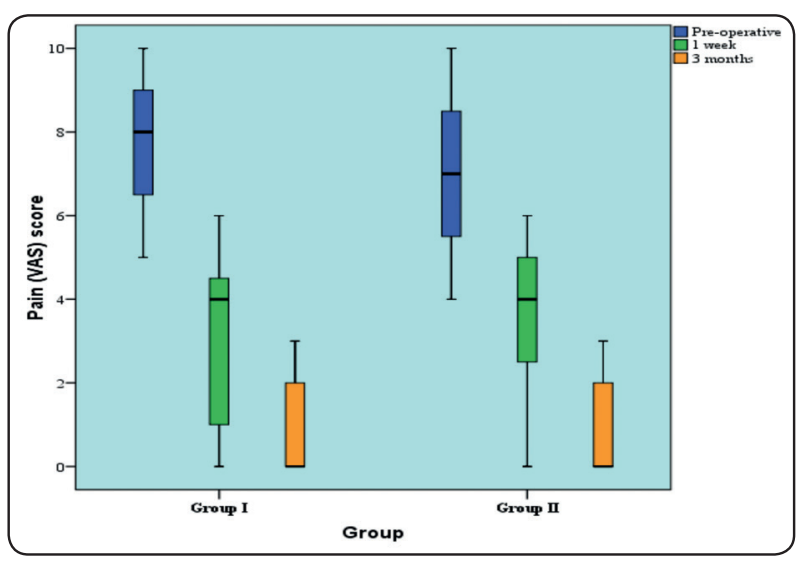

Fig. (1) Box plot representing median and range values for pain scores in the two groups

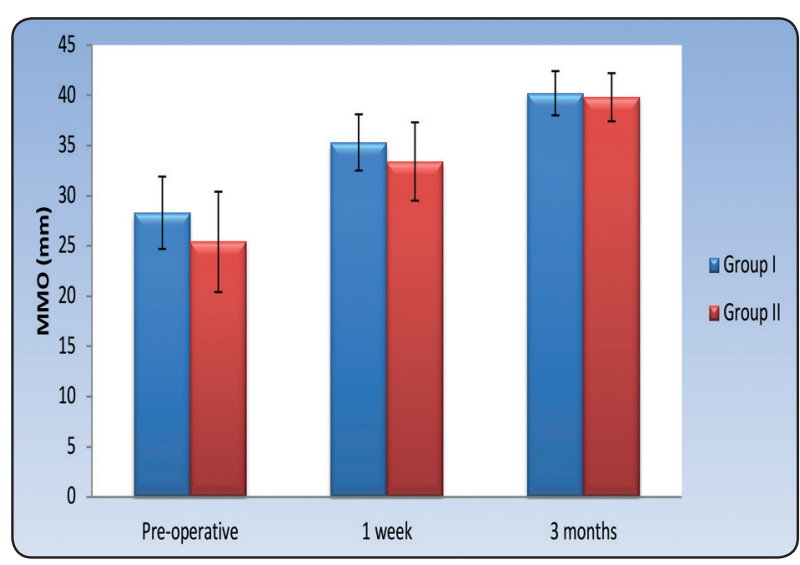

Fig. (2) Bar chart representing mean and standard deviation values for Maximum Mouth Opening (MMO) measurements in the two group

TABLE (3) Descriptive statistics and results of Mann-Whitney U test for comparison between TNF- $\alpha$ concentrations in the two groups and Friedman's test for the changes by time within each group

\begin{tabular}{|c|c|c|c|c|c|c|}
\hline \multirow[t]{2}{*}{ Time } & \multicolumn{2}{|c|}{$\begin{array}{l}\text { Group I } \\
(\mathrm{n}=12)\end{array}$} & \multicolumn{2}{|c|}{$\begin{array}{l}\text { Group II } \\
(\mathrm{n}=12)\end{array}$} & \multirow[t]{2}{*}{$P$-value } & \multirow[t]{2}{*}{ Effect size $(d)$} \\
\hline & Median & Range & Median & Range & & \\
\hline Pre-operative & $0.38^{\mathrm{A}}$ & $0.04-1.71$ & $0.1^{\mathrm{A}}$ & $0.06-1.09$ & 0.840 & 0.083 \\
\hline 1 week & $0.25^{\text {в }}$ & $0.03-0.99$ & $0.09^{\mathrm{A}}$ & $0.06-1.07$ & 0.603 & 0.213 \\
\hline 3 months & $0.06^{\mathrm{C}}$ & $0-0.97$ & $0.06^{\mathrm{B}}$ & $0.05-0.11$ & 0.954 & 0.024 \\
\hline$P$-value (Changes by time) & \multicolumn{2}{|c|}{$0.001 *$} & \multicolumn{2}{|c|}{$<0.001 *$} & & \\
\hline Effect size $(w)$ & \multicolumn{2}{|c|}{0.632} & \multicolumn{2}{|c|}{0.771} & & \\
\hline
\end{tabular}

*: Significant at $P \leq 0.05$, Different superscripts in the same column indicate statistically significant changes by time

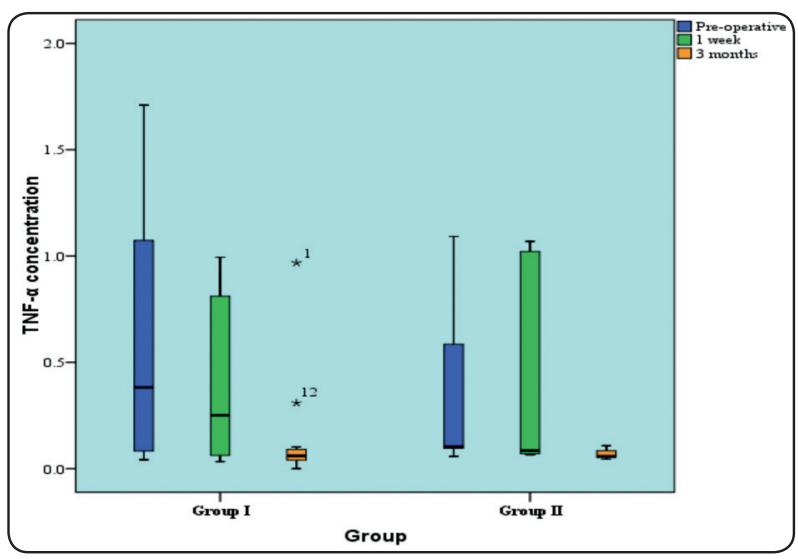

Fig. (3) Box plot representing median and range values for TNF- $\alpha$ concentrations in the two groups (Stars represent outliers)

\section{DISCUSSION}

Reports of alteration in joint lubrication, and / or joint effusion demonstrated by MRI in cases of internal derangement prove the association of joint inflammation in the clinical presentation. Furthermore, biochemical evidence of inflammatory mediators in the synovial fluid support this etiologic pathogenesis $^{(13,48)}$.

In view of the new evidence about TMJ internal derangement, treatment should be directed to pain management, reduction of inflammation, decreasing adverse joint loading and restoration of normal function $^{(50)}$. Changing the position of the disc and 
removal of the disc with or without replacement, although fairly successful are associated with surgical morbidity and potential long term sequalae ${ }^{(7)}$.

In this study assessment of pain and mouth opening were considered during treatment planning as pain intensity and mouth opening proved successful as predictors for the effect of arthrocentesis on joint effusion outcomes ${ }^{(51)}$.

Arthrocentesis proved to be comparable to other procedures for treatment of closed lock ${ }^{(52,53)}$. more over it proved its worth in, relieving dysfunction by lysis of adhesions, washing out of inflammatory mediators and toxic metabolites resulting in decreasing synovitis and reduction of pain. This in turn decreased obstruction caused by anterior displacement via hydraulic distension of the joint. ${ }^{(54,55)}$.

TNF- $\alpha$ was proposed to be used as a pain marker for following patients response to some therapeutics because of its role in mediating both joint inflammation and bone metabolism. Measuring the TNF- $\alpha$ in the SF of the affected joints was performed in this study to reflect the changes in the inflammatory process in the treated joints throughout the treatment course.

Our findings coincide with the evidence that elevated levels of TNF- $\alpha$ in the joint capsule, which is reported to occur in TMD, promotes nociception in trigeminal ganglia ${ }^{(15)}$. In this study the significant postoperative reduction in TNF- $\alpha$ concentrations in the SF samples together with the symptomatic improvement and relief of pain were evident in the two groups throughout the follow up intervals. This indicates the role of this cytokine as a prediction marker for improvement of symptoms. These findings support the concept that synovitis is a cause of the joint pain in patients with TMD which in agreement with further previous studies ${ }^{(8}$, ${ }^{13)}$. In both groups arthrocentesis and drugs injection resulted in symptomatic improvement, evidenced by significant improvement of MMO, joint pain and muscle tenderness from preoperative which could be attributed to the fact that patients with a greater inflammatory component pain $>7, \mathrm{MIO}<25$ $\mathrm{mm}$ and younger patients <25years benefitted more from arthrocentesis ${ }^{(56)}$.Concerning groupI, The results of this study are in accordance with those of previous studies ${ }^{(7,49,57)}$. Significant improvements in MMO and VAS scores were found at 1week and 3 months follow-ups. However, to our knowledge, no previous studies were done concerning the intraarticular injection of Azithromycin in the TMJ with ID. Azithromycin proved to be comparable to corticosteroids in treatment of TMJ ID. However, comparisons between the time periods revealed no statistically significant change in median TNF- $\alpha$ concentrations in group II after one week compared to group I. This could be attributed to the strongest effect of corticosteroids as a steroidal anti-inflammatory and to the short and long-term immunomodulatory effects of the macrolides as shown in both in vivo and in vitro studies, using both animal and human models in different clinical situations ${ }^{(32-34,36,41-43)}$. They provide the majority of the same benefits as a corticosteroid, but do not cause immunosuppression ${ }^{(33)}$.

The statistical analysis revealed no significant difference between the corticosteroid and azithromycin groups regarding improvement of pain and MMO. The relatively small sample size may be considered a potential limitation of the study; but the sample size calculation showed a total sample size of 24 would provide an acceptable percentage power to detect clinically significant differences before and after treatment.The power calculation was only carried out to determine a significant correlation between TNF-concentration and the drugs used; therefore, the validity of the binary logistic regression analysis to study associations between TNF- $\alpha$ concentration and the severity of pain,TNF concentration and limitation of MO, pain and MMO through the whole study period is reduced. Among the main limitations of this study are the short follow-up period. In the current study, patients were only followed for 3 months, and additional studies with longer follow-up and a more comprehensive evaluation of outcomes is needed to assess maintenance of the improvement, the potential of relapses, and the need for further treatment. Despite 
the satisfactory results of the present study, further investigations with a larger sample size are needed to examine different patients with great variation of symptoms and determine if the interventions are beneficial.

\section{CONCLUSION}

The observed increase in synovial fluid TNF- $\alpha$ levels is probably related to the increased inflammatory activity within the joint. Intra-articular injection with Azithromycin compared to corticosteroids seems to be a similarly effective method for treating internal derangement of the TMJ. However, further randomized controlled clinical trials are required before its recommendation in clinical practice to add to the validity needed to help making decision regarding the feasibility of the use of macrolides as an efficient anti-inflammatory treatment and to investigate the real therapeutic effectiveness of these drugs as a non-invasive conservative treatment modalities.

\section{Disclosure Statement}

The authors have no conflicts of interest to disclose.

Funding: no funding agency in support of this research.

\section{ACKNOWLEDGMENT}

The authors would like to thank Dr. Khaled Keraa for his valuable contribution in statistical analysis and Dr Mai Sherif for processing and analysis of synovial fluid analysis.

\section{REFERENCES}

1. Kawai Y, Lee MC, Kubota E. Oxidative stress and temporomandibular joint disorders. Japanese Dental Science Review. 2008; 44:145-150.Doi:10.1016/j.dsr.2008.08.001.

2. Demir CY, Kocac OF, Bozan N, Erzos ME, Demir H. Is There a Role for Oxidative Stress in Temporomandibular Joint Disorders? J Oral Maxillofac Surg. ANESTHESIA/ FACIAL PAIN. March 2018; 76(3): 515-520.

3. Braz MA, Portella FF, Sechaber KA, Bavaresco CS, Rivaldo EG. Association between oxidative stress and temporo- mandibular joint dysfunction: A narrative review.J Oral Rehabil. 2020 Apr; 47(4): 536-546. PMID: 31880832. Doi:10.1111/joor.12930

4. Milam S, Schmitz J. Molecular biology of temporomandibular joint disorders: Proposed mechanisms of disease. J Oral Maxillofac Surg 1995; 53:1448-1454.

5. Lobbezzo F, Drangsho HM, Peck C, Sato H, Kopp S, Sevensson P. Topical review: New insights into the pathology and diagnosis of disorders of the temporomandibular joint. J Orofac Pain 2004; 18: 181-186.

6. Dolowick M. Intraarticular disc displacement part I: Its questionable role in temporomandibular joint pathology. $\mathrm{J}$ Maxillofac Surg1995; 53: 1069-1072

7. Carvajal W, Laskin D. Long term evaluation of arthrocentesis for the treatment of internal derangement of the temporomandibular joint.J Oral Maxillofac Surg 2000;58: 852-855.

8. Suzuki T, Segami N, Nishimura M, Nojima T. Co-expression of interluken-1beta and tumor necrosis factor alpha in synovial tissues and synovial fluids of temporomandibular joint with internal derangement. J Oral Pathol Med 2002;31: 549-553.

9. Swift J, Rosekowski M, Alton T, Hargrewes M. Effect of intraarticular versus systemic anti-inflammatory drugs in a rabbit model of temporomamdibular joint inflammation. $\mathrm{J}$ Oral Maxillofac Surg 1998; 56:1288-1287.

10. Emschoff R, Puffer P, Strobl H, Gassner R. Effect of TMJ arthrocentesis on synovial fluid mediator level of TNF- $\alpha$ : Implications for treatment outcome. Int J Oral Maxillofac Surg. 2000;3:176-180.

11. Shafer D, Assael L, White L, Rossomando E. Tumor necrosis factor-alpha as a biochemical marker of pain and outcomein temporomandibularjoints with internal derangemants. J Oral Maxillofac Surg 1994; 52:786-791.

12. Kaneyama K, Segami N, Nishimura M, Suzuki T, Sato J. Importance of proinflammatory cytokines in synovial fluid from 121 joints with temporomandibular disorders. Br J Oral Maxillofac Surg 2002; 40:418-423.

13. 13. Fu K, Ma X, Zhang Z, Chen W. Tumor necrosis factor in synovial fluid of patients with temporomandibular disorders. J O ral Maxillofac Surg 1995;53:424-426.

14. Nishimura M, Segami N, Kaneyama K, Suzuki T, Miyamaru M. Proinflammatory cytokines and arthroscopic findings of patients with internal derangement and osteoarthritis of the temporomandibular joint. Br J Oral Maxillofac Surg 2002; 40: 68-71. 
15. Durham ZL, Hawkins JL, Durham PL. Tumor Necrosis Factor-Alpha Stimulates Cytokine Expression and Transient Sensitization of Trigeminal Nociceptive Neurons. Archives of oral biology. November 2017;75:100-106. DOI: 10.1016/j.archoralbio.2016.10.034. PMC 5266621

16. Tvrdy P, Heinz P, Pink R. Arthrocentesis of the temporomandibular joint: A review. Biomed Pap Med Fac Univ Palacky Olomouc Czech Repub 2015 Mar; 159(1):31-34.

17. Önder ME, Tüz HH, Koçyigit TD, Kișnișci RS. Long-term results of arthrocentesis in degenerative temporomandibular disorders (Oral Surg Oral Med Oral Pathol Oral Radiol Endod 2009; 107:e1-e5.

18. Briggs KA, Breik O, Ito K, Goss AN. Arthrocentesis in the management of internal derangement of the temporomandibular joint. Australian Dental Journal 2019; 64: 90-95. doi: $10.1111 /$ adj.12665

19. Monje-Gil F, Nitzan D, González-Garcia R. Temporomandibular joint arthrocentesis. Review of the literature. Med Oral Patol Oral Cir Bucal. 2012 Jul 1;17 (4):e575-81. http://www.medicinaoral.com/medoralfree01/v17i4/medoralv17i4p575.pdf

20. Al-Moraissi EA, Wolford LM, Ellis E III, Neff A. The hierarchy of different treatments for arthrogenous temporomandibular disorders: A network meta-analysis of randomized clinical trials. J Cranio-MaxillofaC Surg. 2019 Jan; 48(1):9-23. doi: 10.1016/j.jcms.2019.10.004. Epub 2019 Nov 5. PMID31870713. https://doi.org/10.1016/j. jcms.2019.10.004. https://www.researchgate.net/publication/337025401

21. Hall HD, Indresano AT, Kirk WS, Dietrich MS: Prospective multicenter comparison of 4 TMJ operations. J Oral Maxillofac Surg 2005; 63:1174-1179.

22. Abouelhuda AM, khalifa AK, YK Kim, Hegazy SA. Noninvasive different modalities of treatment for temporomandibular disorders: review of literature. J Korean Assoc Oral Maxillofac Surg 2018; 44:43-51. https://doi.org/10.5125/ jkaoms.2018.44.2.43 PISSN 2234-7550•eISSN 2234-5930.

23. Sembronio S, Albiero AM, Toro C, Robiony M, Politi M. Is there a role for arthrocentesis in recapturing the displaced disc in patients with closed lock of the temporomandibular joint? Oral Surg Oral Med Oral Pathol Oral Radiol Endod 2008; 105: 274-80. doi:10.1016/j.tripleo.2007.07.003

24. Kutuk N, Bas B, Kazan D, Yuceer E. Is Repeated Arthrocentesis Beneficial in the Treatment of Temporomandibular Disorders: A Retrospective Study. J Oral Maxillofac Surg 2019 Jul;77(7):1359-1364. doi: 10.1016/j. joms.2019.01.041. PMID: 30825439. https://doi. org/10.1016/j.joms.2019.01.041

25. Fouda AA. Association between Intra-Articular Corticosteroid Injection and Temporomandibular Joint Structure Changes. Int Arch Oral Maxillofac Surg 2018, 2(1):015019 .

26. Yavuz GY, Kaya GS, Oğul H . A comparison of the effects of Methylprednisolone Acetate, Sodium Hyaluronate and Tenoxicam in the treatment of non-reducing disc displacement of the temporomandibular joint. Med Oral Patol Oral Cir Bucal. 2018 May ;23 (3):e351-8.doi:10.4317/medoral.22237 http://dx.doi.org/doi:10.4317/medoral.22237

27. Machado E, Bonotto D, Cunali PA. Intra-articular injections with corticosteroids and sodium hyaluronate for treating temporomandibular joint disorders: A systematic review. Dental Press J Orthod. 2013 Sept- Oct; 18(5):128-33.

28. Tatli U, Benlidayi ME, Ekren O, Salimov F: Comparison of the effectiveness of three different treatment methods for temporomandibular joint disc displacement without reduction. Int J Oral Maxillofac. Surg. 2017; 46: 603-609.

29. Sewal S R, Ryan D E, Kwon P H, Oyen O J. The effect of intraarticular deposition of betamethasone in the goat temporomandibular joint. J Oral Maxillofac Surg 1995; 53:1435-1439.

30. Fredriksson L, Alstergen P, Kopp S.Tumor necrosis factoralpha in temporomandibular joint synovial fluid predicts treatment effects on pain by intraarticular glucocorticoid treatement. Mediators Inflamm 2006 (6):1-7Article ID 59425. DOI: 10.1155/MI/2006/59425. PIMD17392588.

31. Skarmeta NP, Hormaz_abal FA, Alvarado J, Rodriguez AM. Subcutaneous Lipoatrophy and Skin Depigmentation Secondary to TMJ Intra-Articular Corticosteroid Injection. J Oral Maxillofac Surg 2017;75:2540.e1-2540.e5. http:// dx.doi.org/10.1016/j.joms.2017.07.174

32. Ianaro A, Ialenti A, Maffia P, Sautebin L, Rombola 1, Carnuccio R, Iuvone T, D'Acquisto F, Di Rosa M. Anti-inflammatory activity of macrolide antibiotics. J Pharmacol Experimental Therapeutics 2000 Jan; 292(1):156-163.

33. Amsden G W. Anti-inflammatory effects of macrolidesan underappreciated benefit in the treatment of community-acquired respiratory tract infections and chronic inflammatory pulmonary conditions?. Journal of Antimicrobial Chemotherapy 2005; 55: 10-21. doi:10.1093/jac/dkh519

34. Ertas U, Tozoglu S, Sahin O, Seven B, Gundogdu C, Aktan B, Yildirim N. Evaluation of the anti-inflammatory effect oferythromycin on aseptic inflammation of temporoman- 
dibular joint in rabbit: a scintigrapkic and histopathologic study. Dental Traumatology 2005; 21:213-217.

35. Borszez O, Befus D, Moqbel R, Sin D, Adamko D, Man S, Lacy P. Effects of clarithromycin on inflammatory cell mediator release and survival. Chemotherapy $2005 \mathrm{Jul}$; 5(4):206-210.

36. Urasaki Y, Nori M, Iwata S, Sasaki T, Hosono O, Kawasaki H, Tanaka H, Dang N, Ikeda E, Morimoto C. Roxithromycin specifically inhibits development of collagen induced arthritis and production of proinflammatory cytokines by human T cells and macrophages. J Rheumatol.2005 Sep; 32(9):1765-74

37. RenW, Li X, Wooley P. Erythromycin inhibits wear debrisinduced osteoclastogenesis by modulation of murine macrophage NF-Kappa activity. J Orthop Res 2004 Jan; 22(1): 21-9.

38. Ren W, Wu B, Preng X, Mayton L, Yu D, Chen B, Wooley P. Erythromycin inhibits wear debris- induced imflammatory osteolysis in a murine model. J Orthop Res 2006 Feb;24(2): 280-290.

39. Yamauchi K, Shibata Y, Kimura T, Abe S, Inoue S, Osaka D, Sato M, Igarashi A, and Kubota I. Azithromycin suppresses interleukin-12p40 expression in lipopolysaccharide and interferon- $\gamma$ stimulated macrophages. Int. J. Biol. Sci. 2009; 5(7):667-678. http://www.biolsci.org

40. Kriauciunas A, Gleiznys A, Gleiznys D, Janužis G. The Influence of Porphyromonas Gingivalis Bacterium Causing Periodontal Disease on the Pathogenesis of Rheumatoid Arthritis: Systematic Review of Literature. Cureus 2019; 11: e4775-479. [CrossRef]

41. Scaglione F, Rossoni G. Comparative anti-inflammatory effects of roxithromycin, azithromycin and clarithromycin. J. Antimicrob. Chemother. 1998; 41: 47-50. [CrossRef] [PubMed]

42. Yoshii, T.; Nishimura, H.; Yoshikawa, T.; Furudoi, S.; Yoshioka, A.; Takenono, I.; Ohtsuka, Y.; Komori, T. Therapeutic possibilities of long-term roxithromycin treatment for chronic diffuse sclerosing osteomyelitis of the mandible. J. Antimicrob. Chemother. 2001;47:631-637.

43. Sevilla-Sánchez D, Soy-Muner D, Soler-Porcar N. Usefulness of Macrolides as Anti-inflammatories in Respiratory Diseases. Arch Bronconeumol. 2010; 46(5):244-254

44. Wilkes CH. Internal derangements of the temporomandibular joint. Pathological variations. Archives of Otolaryngology, Head Neck Surgery1989; 115(4)469-477.

45. American Association of Oral and Maxillofacial Surgeons.1984 criteria for TMJ meniscus surgery. Chicago: American Association of Oral and Maxillofacial Surgeons; 1984:1-40.
46. Yilmaz O, Candirli C, BalabanE, Demirkol M. Evaluation of success criteria for temporomandibular joint arthrocentesis. J Korean Assoc Oral Maxillofac Surg 2019; 45:15-20. doi.org/10.5125/jkaoms.2019.45.1.15. PISSN 2234-7550·eISSN 2234-5930

47. Türp JC, Lothaller H, Scioscia A.Maximum mandibular mobility in patients with temporomandibular disorders. Swiss Dental Journal.SSO 2020; 130 (9): 668-675.

48. Melchiorre D, Calderazzi A, Bongi SM, Cristofani R, Bazzichi L, Eligic C, Maresca M, Ciompi ML. Acomparison of ultrasonography and magnetic resonance imaging in the evaluation of TMJ involvement in rheumatoid arthritis and psoriatic arthritis. Rheumatology 2003; 42:673-677.

49. Murakami K, Segami N, Fujimura K. Correlation between pain and synovitis in patients with internal derangement of the temporomandibular joint. J Oral Maxillofac Surg 1991;49: 1159-1164.

50. Ertem SY, Konarılı FN, Ercan KB Does Incidence of Temporomandibular Disc Displacement With and Without Reduction Show Similarity According to MRI Results? J. Maxillofac. Oral Surg. 2020 (Oct-Dec); 19(4):603-608 https://doi.org/10.1007/s12663-019-01322-w

51. Grossmann E, Poluha RL, Iwaki LCV, Santana RG, and Filho LI. Predictors of arthrocentesis outcome on joint effusion in patients with disk displacement without reduction. Oral Surg Oral Med Oral Pathol Oral Radiol 2018;125:382388. https://doi.org/10.1016/j.0ooo.2017.12.021

52. Nitzan D W, Samson B, Better H. Long-term outcome of arthrocentesis for sudden onset, persistant,severe closed lock of the temporomandibular joint. J Oral Maxillofac Surg. 1997; 55:151 -156.

53. Moses JJ, Sartoris D, Glass R. The effect of arthroscopic surgical lysis and lavage of the superior joint space on temporomandibular jointdisc positionand mobility.J Oral Maxillofac Surg 1989; 47: 674-680.

54. Barkin S, Weinberg S. Internal derangement of the temporomandibular joint: The role of arthroscopic surgery and arthrocentesis. J Can Dent Assoc 2000; 66: 199-103.

55. Fridrich K, Wise J, Zeitler D. Prospective comparison of arthroscopy and arthrocentesis for temporomandibular joint disorders. J Oral Maxillofac Surg 1996; 54:816-820.

56. Andrabi SW, Malik AH, Shah AA.Clinical factors affecting the outcome of arthocentesis. J Korean Assoc Oral Maxillofac Surg 2019; 45:9-14. https://doi.org/10.5125/ jkaoms.2019.45.1.9 pISSN 2234-7550•eISSN 2234-5930

57. Dimitroulis G, Dolwick M, Martinez A. TMJ arthrocentesis and lavage for the treatment of closed lock: a follow -up study. Br J Oral Maxillofac Surg, 1995;33:23-28. 